\title{
Surgical practice among pediatric surgeons and pediatric urologists in the Kingdom of Saudi Arabia for the management of suspected testicular torsion
}

Hamdi H. Almaramhy, MBBS, FRCSI.

\begin{abstract}
الأهداف : أجريت هذه الدراسة لمراجعة ومقارنة الممارسات السريرية

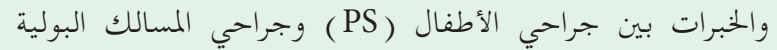

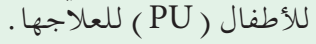

الطريقة : أجريت هذه دراسة مقطعية مستعرضة في الفترة ما بين

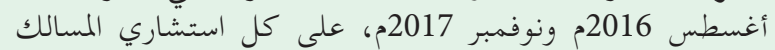

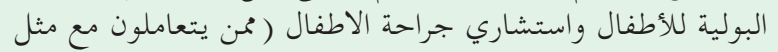

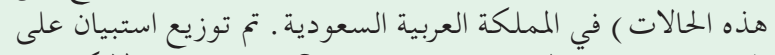

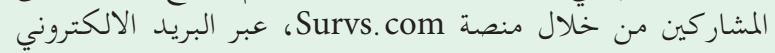
وعبر وسائل التو اصل الحد يثله . لمنية.

النتائج: استخدم معظم جراحي المسالك البولية للأطفال

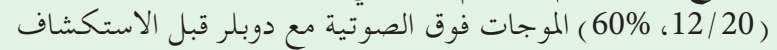

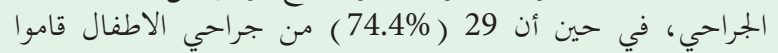

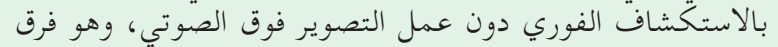

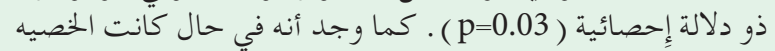

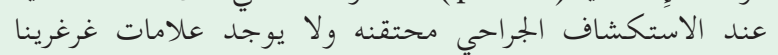

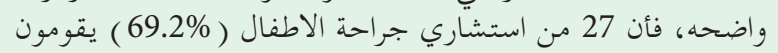

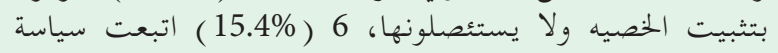

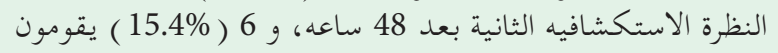

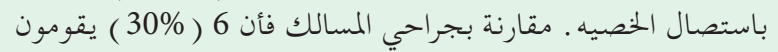

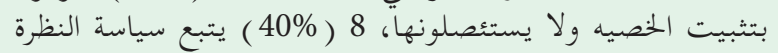

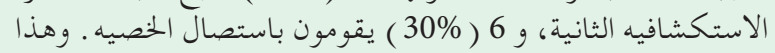

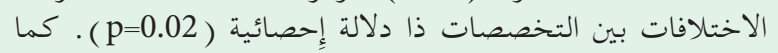
وجد اختلافات أخرى ولكن ليست ذات ذإِ دلالات مهمهـ.

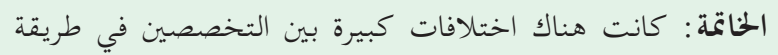

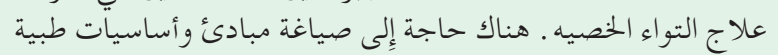

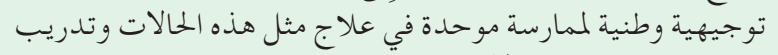

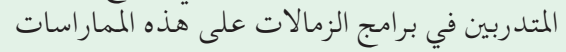

Objectives: To review and compare clinical practice and experience among pediatric surgeons (PS) and pediatric urologists (PU) for the management of testicular torsion (TT) in the Kingdom of Saudi Arabia (KSA).
Methods: This was a cross-sectional study conducted between August 2016 and November 2017, among all PU and PS involved in the management of suspected TT in KSA. A questionnaire was distributed to participants through the Survs.com platform, and direct email when requested by participant.

Results: Most PU (12/20, 60\%) utilized ultrasound with Doppler before exploration, while 29 (74.4\%) PS performed immediate exploration without imaging, representing a statistically significant difference $(p=0.03)$. When the explored testis was dusky (not frank gangrenous), 27 PS (69.2\%) performed fixation, $6(15.4 \%)$ followed the second look policy, and 6 (15.4\%) performed orchiectomy. With respect to PU, 6 (30\%) performed fixation, 8 (40\%) followed the second look policy, and $6(30 \%)$ performed orchiectomy. The differences between the 2 specialties were statistically significant $(p=0.02)$. Most consultants in both specialties performed fixation of the contralateral testis during the same operation. Also, there is a variation in practice when there is other pathology than TT.

Conclusion: There were significant variations between the 2 specialties in the management of TT. National guidelines are needed to provide homogenous clinical practice and training of trainees.

Saudi Med J 2018; Vol. 39 (12): 1232-1237 doi: $10.15537 /$ smj.2018.12.22958

From Division of Pediatric Surgery, Department of Surgery, College of Medicine, Taibah University, Almadinah Al-munawarah, Kingdom of Saudi Arabia.

Received 16th September 2018. Accepted 7th November 2018

Address correspondence and reprint request to: Dr. Hamdi. Almaramhy, Division of Pediatric Surgery, Department of Surgery, College of Medicine, Taibah University, Almadinah Al-munawarah, Kingdom of Saudi Arabia. E-mail:hmaramhy@tiabahu.edu.sa

ORCID ID: orcid.org/0000-0003-2080-122X 
$S^{p}$ permatic cord torsion, commonly known as testicular torsion (TT), is a common emergency that requires precise assessment and urgent clinical decision making. Testicular torsion occurs predominantly in adolescents; however, it can occur at any age. In Korea, the reported incidence in males under 25 years is 2.9 per 100,000 , while in Taiwan and the United States of America the incidence is 3.5 cases per 100,000 people per year and 4.5 cases per 100,000 males per year. ${ }^{1-3}$ Testicular torsion represents approximately $17 \%$ of acute painful scrotum presentations, and TT is diagnosed in $40 \%$ of scrotal explorations for suspected TT. ${ }^{4-5}$ The exact etiology is not yet known, although the anatomical 'bell clapper' deformity, weather changes, and familial history of TT have been suggested as risk factors. ${ }^{6-8} \mathrm{It}$ is universally accepted among surgeons that suspected TT requires urgent surgical exploration. This urgency, however, needs to be balanced with appropriate clinical assessment and proper judgement concerning the use of imaging in order to avoid unnecessary exploration. Nevertheless, there are different views and debates concerning management aspects pertaining to suspected TT and the necessity for contralateral exploration and fixation. Furthermore, proper decision making in case of negative exploration for TT has not been agreed upon in terms of whether it is better to fix versus not to fix the exposed testis and heterogeneity in practice exists. ${ }^{9}$ In the Kingdom of Saudi Arabia (KSA), such cases are managed by PU if specialty is available in the hospital or by a PS if no PU. These specialists have different experiences and training background. Furthermore, survey studies evaluating clinical practice among medical professionals in KSA are scarce. This study was conducted to review and compare the clinical practice and experience of general PS compared to PU in suspected TT case management.

Methods. A cross-sectional survey study was conducted in KSA between August 2016 and November 2017 in order to ascertain views concerning best practices for TT management. The questionnaire was distributed to 114 consultants using the Survs.com platform and via direct emailing experts who requested an e-mail in order to participate in the survey. Only consultants, PS (who managed acute scrotal diseases) and $\mathrm{PU}$, were requested to participate and answer the questionnaire. To be a consultant PS or PU in KSA,

Disclosure. The author have no conflict of interests, and the work was not supported or funded by any drug company. commonly you need to undergo 5 years training program in general surgery or urology followed by 2 or 3 years. Pediatric urologists have been trained on use of ultrasound during their training program and they do ultrasound themselves if the radiologist will take time to come, so there will be no much delay

Participants were asked to complete a questionnaire that was validated based on previous surveys and feedback from 3 expert consultants with some modifications for the purposes of our study. ${ }^{9,10}$ The questionnaire was piloted and tested to ensure reliability. The questionnaire composed of 5 sections, included demographic data, decision making in the approach to suspected TT, practice of fixation of the contralateral testis and timing of fixation, routine practice in case of negative exploration of TT and, the fixation technique and preferred suture used.

Only respondents who completed the questionnaire were included. Approval for the study was obtained from the Institutional Ethics Committee. A PubMed search was performed to identify similar studies and assess gaps in data on this topic.

Statistical analysis. Frequencies and ratios were used to express quantities and qualitative data. The Fisher's exact test, was used to compare between the 2 groups; for descriptive sample data, 95\% confidence interval (CI) were calculated. Two tailed $p$-value of 0.05 was considered statistically significant. All statistical analysis were carried out using Statistical Package for Social Science (SPSS), Version 19.0 (IBM Corp., Armonk, NY, USA).

Results. In total, 114 participants were provided questionnaires; 82 participants responded, yielding an estimated response rate of approximately $72 \%$. Only $59(52 \%)$ respondents completed the survey; 39 (78\%) were PS and $20(22 \%)$ were PU. Questionnaires that were not completed were excluded.

Table 1 summarizes the approach to a patient presenting with acute scrotal disease and the expected management of TT that is not clearly gangrenous and remains dusky during exploration. The majority of PU (12/20, 60\%) performed ultrasound with Doppler prior to exploration, compared to only $10 / 39$ (25\%) of PS, who commonly performed immediate exploration (95\% CI: 13-42.1). The difference between PU and PS was statistically significant $(p<0.03)$. When the findings upon scrotal exploration consisted of dusky testis but no apparent gangrene, the majority of PS (27/39, $69.2 \%$ ) did not remove the testis but performed fixation without second look, while most PU (40\%) followed the 48 hours second look policy (95\% CI: 19.1-54.3). 
Six of 30 (20\%) PS and 6 of 20 (30\%) PU performed orchiectomy. The difference in practice between PS and PU was statistically significant ( $p=0.02)$.

Table 2 reports data on contralateral testis fixation in a 3-sided situation concerning exploration and timing of fixation. The majority of PS and PU performed the same practice with regard to fixing the contralateral testis depending on whether the explored testis was gangrenous or viable. Four out of 39 PS and one out of $20 \mathrm{PU}$ did not fix the contralateral testis when the affected testis was found viable. There was no significant difference between the 2 groups regarding fixation of the contralateral testis whether the explored testis is viable $(p=0.7)$ or gangrenous $(p=0.5)$. When the finding was torsion of hydatid (Morgagni) cyst; most of both groups 35 PS (90\%) and 17 PU (85\%) did not fix the contralateral testis. There was no significant difference between the 2 groups $(p=0.6)$. Nineteen out of 20 (95\%) of PU reported fixation of the contralateral testis during the same operation, compared to $31 / 39$ (79.5\%) of PS. However, 8 (20.5\%) PS performed fixation at a later time on an elective basis. This difference was not significant $(p=0.1)$.

Table 3 reports data on the practice of fixing the explored testis in case of negative scrotal exploration for TT. When the finding was torsion due to hydatid (appendix of the testis), 36/39 (71.8\%) PS fixed the explored side compared to $11 / 20(55 \%)$ of PU. These percentages were similar in cases of epididymo-orchitis or no pathology. Both specialties did not fix the contralateral testis in the above described situations. There was no statistical difference between the 2 groups' practices for fixation of explored testis in case of torsion due to hydatid $(p=0.2)$, epididymo-orchitis $(p=0.11)$, or no pathology $(p=0.15)$.

Table 4 reports the technique used for testicular fixation. Only $7.7 \%$ of PS and $5 \%$ of PU utilized

Table 1 - Decision making practice among pediatric surgeons and pediatric urologists in case of suspected testicular torsion.

\begin{tabular}{|c|c|c|c|c|c|}
\hline \multirow[t]{2}{*}{ Cases } & \multicolumn{2}{|c|}{$\begin{array}{l}\text { Pediatric surgeons } \\
(\mathrm{n}=39)\end{array}$} & \multicolumn{2}{|c|}{$\begin{array}{l}\text { Pediatric urologists } \\
(\mathrm{n}=20)\end{array}$} & \multirow[t]{2}{*}{$P$-value } \\
\hline & n $(\%)$ & $95 \% \mathrm{CI}$ & n (\%) & $95 \% \mathrm{CI}$ & \\
\hline \multicolumn{6}{|l|}{ Suspected case } \\
\hline $\begin{array}{l}\text { Explore immediately without ultrasound } \\
\text { Ultrasound before exploration }\end{array}$ & $\begin{array}{l}29(74.4) \\
10(25.6)\end{array}$ & $\begin{array}{l}57.9-87 \\
13-42.1\end{array}$ & $\begin{array}{r}8(40) \\
12(60)\end{array}$ & $\begin{array}{l}19.1-63.9 \\
36.1-80.9\end{array}$ & 0.03 \\
\hline \multicolumn{6}{|l|}{ TT that remained dusky at exploration } \\
\hline $\begin{array}{l}\text { Always remove it } \\
\text { Never remove but fix it } \\
\text { Follow the } 48 \text {-hour second look policy }\end{array}$ & $\begin{array}{r}6(15.4) \\
27(69.2) \\
6(15.4)\end{array}$ & $\begin{array}{l}5.9-30.5 \\
52.4-83 \\
5.9-30.5\end{array}$ & $\begin{array}{l}6(30) \\
6(30) \\
8(40)\end{array}$ & $\begin{array}{l}11.9-54.3 \\
11.9-54.3 \\
19.1-63.9\end{array}$ & 0.02 \\
\hline
\end{tabular}

Table 2 - Timing and practice of fixation of the contralateral testis among pediatric surgeons and pediatric urologists in case of testicular torsion.

\begin{tabular}{|c|c|c|c|c|c|c|}
\hline \multirow[t]{2}{*}{ Finding at operation } & \multirow{2}{*}{$\begin{array}{c}\text { Fixation of } \\
\text { contralateral } \\
\text { normal testis }\end{array}$} & \multicolumn{2}{|c|}{$\begin{array}{l}\text { Pediatric surgeons } \\
\quad(\mathrm{n}=39)\end{array}$} & \multicolumn{2}{|c|}{$\begin{array}{l}\text { Pediatric urologists } \\
\qquad(\mathrm{n}=20)\end{array}$} & \multirow[t]{2}{*}{$P$-value* } \\
\hline & & n $\quad(\%)$ & $95 \% \mathrm{CI}$ & n $(\%)$ & $95 \% \mathrm{CI}$ & \\
\hline \multirow[t]{2}{*}{ TT with gangrene } & Yes & $36(92.3)$ & $79.1-98.4$ & $19(95)$ & $75.1-99.9$ & \multirow[t]{2}{*}{0.7} \\
\hline & No & $3(7.7)$ & $1.6-20.9$ & $1(5)$ & $0.1-24.9$ & \\
\hline \multirow[t]{2}{*}{ TT with viable testis } & Yes & $35(89.7)$ & $75.8-97.1$ & $19(95)$ & 75.1-99.9 & \multirow[t]{2}{*}{0.5} \\
\hline & No & $4(10.3)$ & $75.8-97.1$ & $1(5)$ & $0.1-24.9$ & \\
\hline \multirow{2}{*}{$\begin{array}{l}\text { Torsion due to hydatid } \\
\text { but normal testis }\end{array}$} & Yes & $4(10.3)$ & $75.8-97.1$ & $3(15)$ & $3.2-37.9$ & \multirow[t]{2}{*}{0.6} \\
\hline & No & $35(89.7)$ & $75.8-97.1$ & $17(85)$ & $84-86$ & \\
\hline \multirow{2}{*}{$\begin{array}{l}\text { Timing of fixation of } \\
\text { the contralateral normal } \\
\text { testis }\end{array}$} & $\begin{array}{l}\text { At the initial } \\
\text { exploration }\end{array}$ & $31(79.5)$ & $63.5-90.7$ & $19(95)$ & 75.1-99.9 & \multirow[t]{2}{*}{0.1} \\
\hline & $\begin{array}{l}\text { Elective at later } \\
\text { surgical session }\end{array}$ & $8(20.5)$ & $9.3-36.5$ & $1 \quad(5)$ & $0.1-24.9$ & \\
\hline
\end{tabular}


sutureless fixation techniques, while $92.3 \%$ of the PS and $95 \%$ of the PU, used some form of suture fixation.

There is no statically significant difference $(p=1)$ of those who used suture fixation, the majority used absorbable sutures (PS: 30/39; 76.9\%) versus (PU: $15 / 20 ; 75 \%)$. The minority used non-absorbable sutures. When sutures were used, 3/0 and 4/0 were preferable by both specialties, and 2-point or 3-point fixations were commonly used with no significant difference between the 2 groups $(p=0.1)$.

Discussion. In the absence of national guidelines for the management of suspected TT and considering the differences in training background of PU and PS, as well as current debate and heterogeneity in the clinical management of acute scrotal disease, this survey was conducted to evaluate routine practice and patient care.
However, the sample size of this survey is small. We aimed to include all PU and those PS who treat such cases; thus the cohort is representative with a response rate of $52 \%$. The time is crucial in these cases and the use of imaging modalities to reach a proper diagnosis in order to avoid negative scrotal exploration should be balanced with the risk of testicular loss if there is TT for more than 6 hours, known as the golden time for testicular salvage.

Based on published animal studies, spermatogenesis is severely affected 4 to 6 hours after torsion and hormonal production is affected 10 to 12 hours after torsion. ${ }^{10}$ In humans, testis viability is reduced after 6 hours, and in cases of acute scrotum, rapid treatment is required to avoid testicular ischemia. ${ }^{11}$ Most delays occur when the surgeon performs ultrasound in order to exclude or prove the diagnosis of TT. In this survey,

Table 3 - Practice of fixation of the explored testis among pediatric surgeons and pediatric urologists in case of negative exploration for testicular torsion.

\begin{tabular}{lcccrrr}
\hline Finding at exploration & $\begin{array}{l}\text { Fixation of the } \\
\text { explored testis }\end{array}$ & \multicolumn{2}{c}{ Pediatric surgeons } & \multicolumn{2}{c}{ Pediatric urologists } & $P$-value* \\
& & $\mathbf{n} \quad(\%)$ & $95 \%$ CI & $\mathbf{n ~ ( \% ) ~}$ & \multicolumn{1}{c}{$95 \%$ CI } & \\
\hline $\begin{array}{l}\text { Torsion of Morgagni cyst } \\
\text { (appendix of testis) }\end{array}$ & No & $11(28.2)$ & $15-44.9$ & $9(45)$ & $23.1-68.5$ & 0.2 \\
Epididymo-orchitis & Yes & $28(71.8)$ & $55.1-85$ & $11(55)$ & $31.5-76.9$ & \\
& No & $36(92.3)$ & $79.1-98.4$ & $15(75)$ & $50.9-91.3$ & 0.11 \\
No pathology & Yes & $3(7.7)$ & $1.6-20.9$ & $5(25)$ & $8.7-49.1$ & \\
& No & $33(84.6)$ & $69.5-94.1$ & $15(75)$ & $50.9-91.3$ & 0.15 \\
\hline & Yes & $6(15.4)$ & $5.9-30.2$ & $5(25)$ & $8.7-49.1$ & \\
\hline
\end{tabular}

*Fisher exact test. TT - testicular torsion, $\mathrm{n}$ - number, $\mathrm{CI}$ - confidence interval.

Table 4 - Practice of fixation of the explored testis among pediatric surgeons and pediatric urologists in case of negative exploration for testicular torsion.

\begin{tabular}{|c|c|c|c|c|c|}
\hline \multirow[t]{2}{*}{$\begin{array}{l}\text { Fixation of the explored } \\
\text { testis }\end{array}$} & \multicolumn{2}{|c|}{$\begin{array}{l}\text { Pediatric surgeons } \\
\qquad(\mathrm{n}=39)\end{array}$} & \multicolumn{2}{|c|}{$\begin{array}{l}\text { Pediatric urologists } \\
\qquad(\mathrm{n}=20)\end{array}$} & \multirow[t]{2}{*}{$P$-value* } \\
\hline & n (\%) & $95 \% \mathrm{CI}$ & $(\%)^{n}$ & $95 \% \mathrm{CI}$ & \\
\hline \multicolumn{6}{|l|}{ Incision } \\
\hline $\begin{array}{l}\text { Transverse } \\
\text { Midline raphe }\end{array}$ & $\begin{array}{l}21(53.9) \\
18(46.1)\end{array}$ & $\begin{array}{l}37.2-69.9 \\
30.1-62.8\end{array}$ & $\begin{array}{r}5(25) \\
15(75)\end{array}$ & $\begin{array}{c}8.7-49.1 \\
50.9-91.3\end{array}$ & 0.05 \\
\hline \multicolumn{6}{|l|}{ Method of fixation } \\
\hline $\begin{array}{l}\text { Sutureless fixation } \\
\text { Fixation with suture }\end{array}$ & $\begin{aligned} & 3(7.7) \\
& 36(92.0)\end{aligned}$ & $\begin{array}{c}1.6-20.9 \\
79.1-98.4\end{array}$ & $\begin{array}{r}1(5) \\
19(95)\end{array}$ & $\begin{array}{c}0.1-24.9 \\
75.1-99.9\end{array}$ & 1.0 \\
\hline \multicolumn{6}{|l|}{ Sutures used for fixation } \\
\hline $\begin{array}{l}\text { Absorbable } \\
\text { Non-absorbable }\end{array}$ & $\begin{array}{r}30(76.9) \\
9(23.1)\end{array}$ & $\begin{array}{l}60.7-88.9 \\
11.1-39.3\end{array}$ & $\begin{array}{r}15(75) \\
5(25)\end{array}$ & $\begin{array}{l}50.9-91.3 \\
8.7-99\end{array}$ & 1.0 \\
\hline \multicolumn{6}{|l|}{ Suture size } \\
\hline $\begin{array}{l}3 / 0 \\
4 / 0 \\
5 / 0 \\
\text { Others }\end{array}$ & $\begin{array}{r}13(33.3) \\
15(38.5) \\
9(23.1) \\
2 \quad(5.1)\end{array}$ & $\begin{array}{c}19.1-50.2 \\
23.4-55.4 \\
11.1-39.3 \\
0.6-17.3\end{array}$ & $\begin{array}{r}4(20) \\
14(70) \\
2(10) \\
0 \quad(0)\end{array}$ & $\begin{array}{c}5.7-43.7 \\
45.7-88.1 \\
1.2-31.7\end{array}$ & 0.1 \\
\hline
\end{tabular}


a significant difference was found between PS and PU regarding this point. Most PU performed an ultrasound to examine the testis before exploration, while most PS performed urgent exploration without imaging. This difference may be related to the experience of the urologist in performing ultrasound themselves or the availability of ultrasound service at night in high volume hospitals, where most PU work. This finding should be interpreted with caution, as we do not know the rates of negative exploration and orchiectomies in both groups, and thus cannot accurately judge the rate of delayed or unnecessary exploration. In a survey performed in Northwest England concerning TT practice management, only 4 of 29 consultant urologists performed ultrasound before exploration. ${ }^{12}$ Doppler ultrasonography for the diagnosis of TT demonstrated $94 \%$ sensitivity, $96 \%$ specificity, $95.5 \%$ accuracy, a $89.4 \%$ positive predictive value, and a $98 \%$ negative predictive value. ${ }^{13}$ Kalfa et $a l,{ }^{14}$ reported that twisted testis can be detected in 96\% of cases with high-resolution ultrasonography and in $76 \%$ of cases with color Doppler ultrasound. Although ultrasound may prevent unnecessary exploration, it is still operatordependent and usually not readily available at night and in an emergency room.

Another significant difference between groups involved cases in which intra-operative findings showed TT in which testis were found to be dusky but not clearly gangrenous. In these cases, most PU aimed to preserve the testis and perform a second look exploration after 48 hours; however, most PS fixed the testis without performing a second look. Woodruff et $\mathrm{al},{ }^{15}$ reported a case in which the explored testis was looked subjectively dead and the decision was to fix it, post-operative follow up at 4 and 12 weeks for that case demonstrated normal testosterone levels and normal intratesticular blood flow by ultrasound. Rouzrokh et $\mathrm{al},{ }^{16}$ reported that in 70 out of 124 boys who underwent scrotal exploration and second look surgery, 44 (63\%) were salvaged. Both strategies (fixing apparently dead testis or second look operation), may help in increasing testicular salvage rate.

The vast majority of responding surgeons performed contralateral fixation to the other testis upon initial exploration, with the exception of some general surgeons who fixed the contralateral testis on an elective base at a later time. This approach involving fixation of the contralateral testis is the universally accepted method of practice. ${ }^{17}$ However, in the past, Arnbjörnsson et $\mathrm{al},{ }^{18}$ disagreed with exploration and fixation of the contralateral testis. Four general surgeons and one urologist did not report fixation of the contralateral testis if the explored, affected testis was viable. In a survey concerning the practice in United Kingdom and Ireland, 4\% (4/97) of surgeons reported that they do not fix the contralateral side. ${ }^{19}$

In cases of negative exploration (namely, in cases with diagnoses other than TT), there was variations between surgeons even within the same specialty. There is no consensus regarding fixation of the explored testis and, to a lesser extent, the contralateral testis. This heterogeneity was also reported by Naumann et al, ${ }^{9} 73$ patients who underwent exploration, 52 were negative, 29 of them underwent fixation of the explored side and 7 underwent contralateral orchidopexy.

Numerous methods have been used by surgeons to fix the testes and prevent re-torsion, including: 1) dartos pouch; 2) eversion of tunica vaginalis; 3 ) suture fixation using 1-, 2-, or 3-point fixation; 4) 4-point axial fixation; or 5) modifications of the above mentioned techniques. ${ }^{20-23}$ There is still controversy concerning the most appropriate fixation technique. In a survey conducted by Bolln et al, ${ }^{19}$ on operative practices while managing TT, $88 \%$ of PS used suture fixation either alone or in combination with other techniques, such as eversion of the tunica vaginalis or creation of a dartos pouch, and only $15 \%$ used a sutureless method for testicle fixation. In a review article by Sells et al, ${ }^{24}$ recurrence of torsion after fixation was found to be more common in cases where absorbable sutures were used compared to cases in which non-absorbable sutures were used. Some authors recommend the use of non-absorbable sutures for fixation. ${ }^{12,25-27}$ In Kingdom of Saudi Arabia, the most common practice is to use absorbable sutures, consisting of $3 / 0$ or $4 / 0$, and 2 or 3 points for fixation. Nevertheless, the adverse effects of suturing through the testicular parenchyma are still questioned. Couglin et $\mathrm{al}^{28}$ reported that the use of suture in orchiopexy was strongly associated with infertility. The right endocrine marker to assess testicular function should be the level of inhibin $\mathrm{B}$ and that a national consensus should state that the level of inhibin B should be measured out postoperatively.

Recommendations from the European Society for Paediatric Urology (ESPU) in this subject state the "use of Doppler ultrasound without delaying the surgical exploration". Moreover, the most recent ESPU guidelines show that there is controversy on whether to carry out detorsion and preserve the ispilateral testis, or to perform an orchiectomy in order to preserve function and fertility of the contralateral testis if symptoms duration is over 24 hours. Regarding the type of fixation and suture material, there is no clear recommendation. ${ }^{29}$

Study limitations. The number of respondents who completed the questionnaire is small, despite a great 
effort was exerted to include all consultants PU and PS (who deals with TT) working in Kingdom of Saudi Arabia. Hence the results of this study should not be generalized to all PS or PU working inside or outside of Kingdom of Saudi Arabia. Furthermore, the results of this cross-sectional design should be interpreted cautiously within the limitations of the survey study design, which is susceptible to bias due to a low response rate and misclassifications due to recall bias. The low response rate was addressed by measuring the 95\% CI, which gives insight into the probability of the total participant population.

In conclusion, this study demonstrated that there is a variation in the practice of TT management among PS and PU in KSA. We need to establish national guidelines concerning the approach to such cases in order to ensure the best patient care. Moreover, these guidelines will help trainees who first face this emergency to handle these cases in the most efficacious manner. Other points that warrant attention during training are the variations in practice between surgeons within the same specialty when facing diagnosis other than TT during scrotal exploration, in order to provide optimal patient care.

Acknowledgment. The author would like to thank Editage (www.editage.com) for English Language editing.

\section{References}

1. Lee SM, Huh JS, Baek M, Yoo KH, Min GE, Lee HL, et al. A nationwide epidemiological study of testicular torsion in Korea. J Korean Med Sci 2014; 29: 1684-1687.

2. Huang WY, Chen YF, Chang HC, Yang TK, Hsieh JT, Huang $\mathrm{KH}$. The incidence rate and characteristics in patients with testicular torsion: a nationwide, population-based study. Acta Paediatr 2013; 102: e363-e367.

3. Mansbach JM, Forbes P, Peters C. Testicular torsion and risk factors for orchiectomy. Arch Pediatr Adolesc Med 2005; 159: 1167-1171.

4. Van Glabeke E, Khairouni A, Larroquet M, Audry G, Gruner M. Acute scrotal pain in children: results of 543 surgical explorations. Pediatr Surg Int 1999; 15: 353-357.

5. Watkin NA, Reiger NA, Moisey CU. Is the conservative management of the acute scrotum justified on clinical grounds? Br J Urol 1996; 78: 623-627.

6. Caesar RE, Kaplan GW. Incidence of the bell-clapper deformity in an autopsy series. Urology 1994; 44: 114-116.

7. Chen JS, Lin YM, Yang WH. Diurnal temperature change is associated with testicular torsion: a nationwide, population based study in Taiwan. J Urol 2013; 190: 228-232.

8. Cubillos J, Palmer JS, Friedman SC, Freyle J, Lowe FC, Palmer LS. Familial testicular torsion. J Urol 2011; 185: 2469-2472.

9. Naumann DN, Jones SA, Taylor C, Jaganathan R, Hendrickse $\mathrm{CW}$, Karandikar S. Heterogeneity in practice during negative scrotal exploration for clinically-suspected testicular torsion. Surg Pract 2015; 19: 64-68.
10. Jensen R, Ellebæk M, Rasmussen L, Qvist N. Low success rate of salvage surgery for testicular torsion in newborns. Dan Med J 2015; 62: A4997.

11. Kallerhoff M, Gross AJ, Bötefür IC, Zöller G, Weidner W, Holstein AF, et al. The influence of temperature on changes in $\mathrm{pH}$, lactate and morphology during testicular ischaemia. $\mathrm{Br} \mathrm{J}$ Urol 1996; 78: 440-445.

12. Pearce I, Islam S, McIntyre IG, O’Flynn KJ. Suspected testicular torsion: a survey of clinical practice in North West England. J R Soc Med 2002; 95: 247-249.

13. Yagil Y, Naroditsky I, Milhem J, Leiba R, Leiderman M, Badaan S, et al. Role of Doppler ultrasonography in the triage of acute scrotum in the emergency department. J Ultrasound Med 2010; 29: 11-21.

14. Kalfa N, Veyrac C, Lopez M, Lopez C, Maurel A, Kaselas C, et al. Multicenter assessment of ultrasound of the spermatic cord in children with acute scrotum. J Urol 2007; 177: 297-301; discussion 301.

15. Woodruff DY, Horwitz G, Weigel J, Nangia AK. Fertility preservation following torsion and severe ischemic injury of a solitary testis. Fertil Steril 2010; 94: 352. e4-e5.

16. Rouzrokh M, Mirshemirani A, Khaleghnejad-Tabari A. Outcomes of Second Look Exploration in Testicular Torsion of Children. Iran J Pediatr 2015; 25: e528.

17. Lavallee ME, Cash J. Testicular torsion: evaluation and management. Curr Sports Med Rep 2005; 4: 102-104.

18. Arnbjörnsson E, Kullendorff CM. Testicular torsion in children--bilateral or unilateral operation. Acta Chir Scand 1985; 151: 425-427.

19. Bolln C, Driver CP, Youngson GG. Operative management of testicular torsion: current practice within the UK and Ireland. J Pediatr Urol 2006; 2: 190-193.

20. Hamdy FC, Hastie KJ. TTorsion of the testis: a new technique for fixation. Eur Urol 1994; 25: 338-339.

21. Antao B, MacKinnon AE. Axial fixation of testes for prevention of recurrent testicular torsion. Surgeon 2006; 4: 20-21, 62.

22. Morse TS, Hollabaugh RS. The "window" orchidopexy for prevention of testicular torsion. J Pediatr Surg 1977; 12: 237-240.

23. Fehér ÁM, Bajory Z. A review of main controversial aspects of acute testicular torsion. J Acute Dis 2016; 5: 1-8.

24. Sells H, Moretti KL, Burfield GD. Recurrent torsion after previous testicular fixation. ANZ J Surg 2002; 72: 46-48.

25. Kapoor S. Testicular torsion: a race against time. Int J Clin Pract 2008; 62: 821-827.

26. Visser A. J HCF. Torsion of the testis and its appendages: diagnosis and management. African J Urol 2004; 10: 85-91.

27. Mongiat-Artus P. [Torsion of the spermatic cord and testicular annexes]. Ann Urol (Paris) 2004; 38: 25-34. [French]

28. Coughlin MT, Bellinger MF, LaPorte RE, Lee PA. Testicular suture: a significant risk factor for infertility among formerly cryptorchid men. J Pediatr Surg 1998; 33: 1790-1793.

29. Tekgül S, Dogan HS, Hoebeke P, Kocvara R, Nijman JM, Radmayr C, et al. EAU Guidelines on Paediatric Urology [Internet]. EAU; 2016 [Accessed 2018 Sep 28]. Available from: https://uroweb.org/wp-content/uploads/EAU-GuidelinesPaediatric-Urology-2016-1.pdf 